\title{
The effects of growing up on a farm on adult lung function and allergic phenotypes: an international population-based study
}

\author{
B Campbell, ${ }_{1}^{1}$ C Raherison, ${ }^{2}$ C J Lodge, ${ }^{1,3}$ A J Lowe, ${ }^{1,3}$ T Gislason, $_{1}^{4,5}$ J Heinrich, $_{1}^{6,7}$ \\ J Sunyer, ${ }^{8,9,10} \mathrm{~F}$ Gómez Real, ${ }^{11,12} \mathrm{D}$ Norbäck, ${ }^{13} \mathrm{M}$ C Matheson, ${ }^{1} \mathrm{M}$ Wjst, ${ }^{14}$ \\ J Dratva, ${ }_{1}^{15,16} \mathrm{R}$ de Marco, ${ }^{17} \mathrm{D}$ Jarvis, ${ }^{18} \mathrm{~V}$ Schlünssen, ${ }^{19} \mathrm{C}$ Janson, ${ }^{11} \mathrm{~B}$ Leynaert, ${ }^{20}$ \\ C Svanes, ${ }^{11}$ S C Dharmage ${ }^{1}$
}

For numbered affiliations see end of article.

\section{Correspondence to} Professor Shyamali C Dharmage, Allergy \& Lung Health Unit, Centre for Epidemiology \& Biostatistics, The University of Melbourne, 207 Bouverie St, Carlton, VIC 3053, Australia

CS and SCD are equal senior authors.

Received 9 December 2015 Revised 6 July 2016 Accepted 22 July 2016 Published Online First 26 September 2016

\section{SLinked}

- http://dx.doi.org/10.1136/ thoraxjnl-2016-209280

\section{CrossMark}

To cite: Campbell $B$,

Raherison C, Lodge C J,

et al. Thorax 2017;72:236-

244.

\section{ABSTRACT}

Rationale Evidence has suggested that exposure to environmental or microbial biodiversity in early life may impact subsequent lung function and allergic disease risk.

Objectives To investigate the influence of childhood living environment and biodiversity indicators on atopy, asthma and lung function in adulthood.

Methods and measurements The European Community Respiratory Health Survey II investigated 10 201 participants aged 26-54 years from 14 countries, including participants' place of upbringing (farm, rural environment or inner city) before age 5 years. A 'biodiversity score' was created based on childhood exposure to cats, dogs, day care, bedroom sharing and older siblings. Associations with lung function, bronchial hyper-responsiveness (BHR), allergic sensitisation, asthma and rhinitis were analysed.

Main results As compared with a city upbringing, those with early-life farm exposure had less atopic sensitisation (adjusted OR $0.46,95 \% \mathrm{Cl} 0.37$ to 0.58 ), atopic BHR (0.54 (0.35 to 0.83$))$, atopic asthma (0.47 (0.28 to 0.81$))$ and atopic rhinitis (0.43 (0.32 to 0.57$))$, but not non-atopic outcomes. Less pronounced protective effects were observed for rural environment exposures. Women with a farm upbringing had higher $\mathrm{FEV}_{1}$ (adjusted difference $110 \mathrm{~mL}$ (64 to 157)), independent of sensitisation and asthma. In an inner city environment, a higher biodiversity score was related to less allergic sensitisation.

Conclusions This is the first study to report beneficial effects of growing up on a farm on adult $\mathrm{FEV}_{1}$. Our study confirmed the beneficial effects of early farm life on sensitisation, asthma and rhinitis, and found a similar association for BHR. In persons with an urban upbringing, a higher biodiversity score predicted less allergic sensitisation, but to a lesser magnitude than a childhood farm environment.

\section{INTRODUCTION}

A dramatic rise in asthma and allergic disease over recent decades has motivated extensive research into the aetiological factors responsible for these conditions. Various hypotheses have been put forth to explain this rise in allergic disease with respect to early-life exposures. Recent evidence has

\section{Key messages}

What is the key question?

- What is the relative impact of early-life farm exposure and other biodiversity proxies on adult lung function and bronchial hyper-responsiveness (BHR)?

What is the bottom line?

- This is the first study to report beneficial effects of growing up on a farm on adult $\mathrm{FEV}_{1}$ and compare biodiversity proxy exposures for inner city participants to confirm the beneficial effects of early farm life on sensitisation, asthma, rhinitis and BHR.

\section{Why read on?}

- This study describes the associations between early-life farm or microbial proxy exposures and adult measures of clinical lung function, BHR and allergic disease to help define the role of microbial biodiversity and farm exposure on adult lung function outcomes.

indicated that the level of exposure to environmental or microbial biodiversity in early life may impact the subsequent risk of allergic outcomes. This hypothesis was initially generated by the observation of an inverse association between family size and hay fever, and has since been coined the 'hygiene hypothesis'. ${ }^{1}$ This work has been subsequently expanded as the microbial hypothesis by observations on the links between exposure to farming environments and a reduction in allergic diseases. The 'farm effect' has been observed by a number of studies, the majority of which have focused on childhood farm exposure and disease onset in childhood, while fewer studies have investigated the impact of early-life exposures on adult disease phenotypes. ${ }^{2}{ }^{3}$ Exposure to increased loads of microbes such as viral, bacterial and parasitic agents associated with farming environments has been proposed as contributing factors in this link, and previous studies have explored various routes of exposure associated with farm life 
more thoroughly to investigate their relative contributions to this 'farm effect'. ' Supporting this hypothesis, studies have also shown that endotoxin and fungal loads in farming homes are significantly higher than those in non-farming homes. ${ }^{4-8}$

Following the interest in early life as a critical window for exposures that determine lifelong health and disease status, numerous studies have investigated the associations between childhood farm exposure and childhood allergic diseases. Systematic reviews synthesising considerable evidence from studies on early-life farm exposure and childhood disease outcomes have shown a decreased risk of asthma, wheeze and allergic disease associated with the 'farm effect'. ${ }^{3}$ However, fewer studies have analysed the impact of these childhood exposures on well-defined allergic adulthood outcomes or the potential persistence of the 'farm effect' into adult life. ${ }^{2}{ }^{39}$ While the majority of existing research has investigated allergic outcomes including asthma, little work has been conducted on the association between early-life farm exposure and clinical measures of lung function in childhood, adolescence or adulthood. ${ }^{10-14}$ Findings in younger cohorts have been conflicting, with one study finding no improvements in spirometric measures related to the 'farm effect', ${ }^{12}$ another study showing only higher FVC in children born on a farm ${ }^{14}$ and a third study finding a lower prevalence of bronchial hyper-responsiveness (BHR) in adolescents raised on a farm-a finding that was more distinct in girls. ${ }^{13}$ Although few articles have completely stratified this association by atopy to investigate this association among atopic and non-atopic groups, in a study on farming environments childhood health outcomes, Fuchs et $a l^{12}$ found that farm exposure reduced risk of wheeze independent of atopic status and observed a statistically significant interaction between atopy and fractional exhaled nitric oxide, but not lung function or BHR. In this under-researched area, only one study has investigated the association between early-life farm exposure and adult lung function, finding no statistically significant results. ${ }^{11}$ This study also found no association between a farm upbringing and risk of BHR. The only other study on this topic found decreased odds of adult BHR, with being 'born and raised' on a farm. ${ }^{10}$ Additionally, many studies on farming exposures and allergic disease outcomes rely on comparisons between categorised 'farming' and 'non-farming' communities, which may overlook the significance of intermediary rural exposures. This is an important distinction in the context that increasing urbanisation is linked to a higher prevalence of allergic disease ${ }^{15}$ Moreover, the strength of the 'farming effect' is not often compared with the other associated early-life exposures related to environmental biodiversity such as pet keeping, older siblings, bedroom sharing and interactions with other children through day care or nursery school attendance. ${ }^{16-18}$ As such, it is currently unclear if exposures to an increased microbial load in an urban setting might approximate the effect of early-life farming exposure on allergic and respiratory disease outcomes.

In this article, we aim to add knowledge to these gaps in this field of research using the European Community Respiratory Health Survey (ECRHS), the largest international multicountry study of adult asthma, collected information on early childhood exposure to farming and place of upbringing. In addition, information was collected on other environmental exposures related to biodiversity and microbial load along with objective outcome measures of IgE-mediated sensitisation and lung function in adult life. Using these data, we aimed to investigate whether exposure to farming is related to adult allergic outcomes and lung function, and if so, whether any associations can be explained by microbial proxy markers.

\section{METHODS}

\section{Study design and data collection tools}

The methods of the ECRHS I have been fully described elsewhere. ${ }^{19}{ }^{20}$ Briefly, in the ECRHS I, participating centres randomly selected samples of participants aged 20-44 years, from a total of 48 centres in 22 countries during 1991-1993. A sampling frame randomly selected 1500 men and women from preexisting administrative boundaries with a population of at least 150000 people, who were mailed a short postal questionnaire about asthma and asthma-like symptoms (stage 1). During stage 2 , a random subsample, made up of roughly $20 \%$ of stage 1 respondents were invited to attend a local testing centre to complete a more detailed questionnaire administered by an interviewer and undergo skin prick and blood tests, assessment of lung function by spirometry and methacholine challenge testing. In addition, participants who were not in the random sample, but who reported current use of treatment for asthma, an asthma diagnosis, or who they had been woken with shortness of breath in the previous 12 months (symptomatic sample) were also invited to participate in stage 2 .

The ECRHS II, conducted between 1998 and 2002, was a follow-up of the clinical participants included in the ECRHS I. Twenty-nine centres participated in this follow-up, where participants underwent a self-completed screening questionnaire, an administered clinical interview, lung function testing and serum $\operatorname{IgE}$ analysis. Clinical measures used in this analysis were collected during the ECRHS II follow-up. The data on early-life farm exposure and current respiratory symptoms that were used in this analysis were also collected in this survey. The detailed protocol can be found at http://www.ecrhs.org.

\section{lgE measurements}

Using the Pharmacia CAP System (Pharmacia Diagnostics AB, Uppsala, Sweden), total serum IgE and specific IgE levels to cat, house dust mite (Dermatophagoides pteronyssinus), mould Cladosporium and timothy grass were measured. Each sample was handled in a similar manner, with centrifugation and subsequent storage at $-20^{\circ} \mathrm{C}$ until $\mathrm{IgE}$ analysis. The serum-level measurement range for total $\mathrm{IgE}$ was $2-2000 \mathrm{kU} / \mathrm{L}$ and 0.35 $100 \mathrm{kUA} / \mathrm{L}$ for specific IgE.

\section{Lung function}

Lung function was assessed by spirometry, and the maximum $\mathrm{FEV}_{1}$ and FVC were measured through a maximum of five acceptable tests.

BHR was measured by methacholine challenge testing. Methacholine was released via a Mefar dosimeter (Mefar, Bovezzo, Italy). Two minutes after each inhalation, $\mathrm{FEV}_{1}$ was recorded, and the test was stopped when either a $20 \%$ fall in $\mathrm{FEV}_{1}$ was achieved or the final methacholine dose had been given.

\section{DEFINITIONS}

\section{Outcomes}

BHR was defined by a fall of at least $20 \%$ in $\mathrm{FEV}_{1}$ after the methacholine challenge test (accumulated dose $1 \mathrm{mg}$ ), and allergic sensitisation was characterised by at least one positive test to any specific allergen $(\geq 0.35 \mathrm{kUA} / \mathrm{L})$. Nasal allergies were determined by questionnaire with response to "Do you have any nasal allergies including 'hayfever'?". Current asthma was defined as BHR AND current wheeze OR the use of asthma medications in the last 12 months. ${ }^{21}$ Participants were classified as having current wheeze if they answered yes to the question 
"Have you had wheezing or whistling at any time during the last 12 months?". Continuous measures of $\mathrm{FEV}_{1}, \mathrm{FVC}$ and $\mathrm{FEV}_{1} / \mathrm{FVC}$ were used in this analysis. The outcomes of asthma, rhinitis and BHR were stratified into allergic and non-allergic phenotypes based on the presence or absence of allergic sensitisation as defined above.

\section{Primary exposure}

For this analysis, participants were grouped by place of upbringing before the age of 5 years as reported in the ECRHS II follow-up survey. The question that collected the participant's childhood living environment was "What term describes the place you lived most of the time when you were under the age of 5 years? (a) farm (b) village in a rural area (c) small town (d) suburb of a city and (e) inner city". A three-level variable was used in the analysis with inner city, farm and a combined intermediary category of village, town or suburb. Similar findings and no statistically significant differences in outcomes were observed between the three intermediary groups when investigated individually. A small, but insignificant, difference was observed between suburb and village with suburbs having a lower benefit than village.

\section{Other exposures}

The 'proxy microbial load score' was calculated from answers to the following survey questions from the ECRHS II: (a) "At what age did you first attend a school, play school, day care or nursery?" (=1 if attended before age 5); (b) "Was there a dog/ cat in your home during your first year of life OR when you were aged 1 to 4 years OR when you were aged 5-15 years?" (=1 for each affirmative answer) (c) "How many other children regularly slept in your bedroom before you were five years old?" $(=1$ if $>0)$ and (d) "How many older brothers (or sisters) [do you have]?" $(=1$ if $>0)$. The combined effect of daycare, pets, bedroom sharing and siblings in early life was examined together as the cumulative 'proxy microbial load score'. Individuals were given a score for the number of factors $(0,1$, 2, 3, 4, 5 exposures).

\section{Analytical methods}

The significance of variation in baseline demographics by earlylife residence was assessed with $\chi^{2}$ tests or analysis of variance methods. Multiple and multinomial logistic regression analyses were performed to estimate adjusted ORs for the associations between childhood environment and clinical phenotypes while adjusting for relevant confounders. Multiple linear regression was performed to estimate the mean differences in lung function by differing early-life home environments while adjusting for possible confounders. A potential interaction between sex and childhood environment was investigated, and a stratified analysis was presented in the presence of a significant interaction. Sensitivity analyses were performed with adjustment for random and symptomatic sample membership and were consistent with the presented findings.

For all analyses, the following a priori confounders were included: age, sex, study centre, smoking status and family history of allergic disease. In addition, height ${ }^{2}$ was determined to be an a priori confounder in the analysis of lung function data. A set of potential confounders were also explored during the analyses and were only included in the final model if the point estimate changed by more than $10 \%$; these variables included maternal/paternal smoking, older siblings or bedroom sharing, early day care or nursery school attendance, early-life cat/dog ownership, socioeconomic status and weight in lung function analyses. Potential heterogeneity of associations was studied across countries. A fixed-effect model was used to meta-analyse risk estimates when there was no significant heterogeneity based on the $\mathrm{I}^{2}$ value $(<50 \%)$ in order to compare risk estimates across participating countries.

A subgroup analysis, limited to those with inner city upbringing in the first 5 years, was performed using a score of microbial load and diversity exposures to evaluate whether the potential risk reduction in the outcomes is similar to any risk reduction related to exposure to farming.

All analyses were carried out using Stata V.12 (StataCorp, College Station, Texas).

\section{RESULTS}

Of the 10201 participants with survey data for the question on childhood living environment, the majority reported living in a village in a rural area, small town or suburb of a city before the age of 5 years $(63.9 \%)$. The percentage of inner city participants was $26.9 \%$ and the smallest group was those living on farms at 9.2\%. Farm-exposed participants were significantly older at follow-up than those born in rural or inner city environments (table 1). The prevalence of exposure to dogs or cats during childhood, older siblings or bedroom sharing with older children was also higher in those who reported living on a farm environment before the age of 5 years. In addition, a family history of allergic disease was less prevalent in this group.

\section{Allergic phenotypes}

A lower prevalence of any allergic sensitisation $(\mathrm{p}<0.001)$, nasal symptoms $(p<0.001)$ or BHR $(0.002)$ was observed in participants reporting farm exposure before the age of 5 (table 2). Those who lived on a farm before the age of 5 years had a reduced risk $(\mathrm{OR}=0.4695 \% \mathrm{CI} 0.37$ to 0.58$)$ of adult atopy compared with those living in the inner city (table 2). Only a moderate reduction was observed in adults from a village/town/ suburb. Stratification of nasal symptoms by sensitisation showed

Table 1 Characteristics and demographic data for the study population, according to childhood living environment

\begin{tabular}{|c|c|c|c|c|}
\hline & $\begin{array}{l}\text { Inner city, } \\
\text { mean (SD) }\end{array}$ & $\begin{array}{l}\text { Village/town/ } \\
\text { suburb, } \\
\text { mean (SD) }\end{array}$ & $\begin{array}{l}\text { Farm, mean } \\
\text { (SD) }\end{array}$ & p Value* \\
\hline \multirow[t]{2}{*}{ Mean age, years } & $41.9(7.2)$ & $42.6(7.2)$ & $45.1(6.4)$ & $<0.001$ \\
\hline & $\%$ (n) & $\%$ (n) & $\%$ (n) & \\
\hline \multicolumn{5}{|l|}{ Gender } \\
\hline Male & 45.5 (1201) & $48.0(2991)$ & $46.8(432)$ & \\
\hline Female & 54.5 (1441) & $52.0(3239)$ & $53.3(492)$ & 0.085 \\
\hline Ever smoker & $57.4(1512)$ & $56.3(3505)$ & $54.3(501)$ & 0.262 \\
\hline Paternal smoking & $66.5(1705)$ & $65.3(3932)$ & $61.0(541)$ & 0.019 \\
\hline Maternal smoking & $27.8(726)$ & $23.1(1415)$ & 14.0 (128) & $<0.001$ \\
\hline Cat in childhood & $32.2(717)$ & $44.3(2772)$ & $84.0(743)$ & $<0.001$ \\
\hline Dog in childhood & $30.1(677)$ & $42.8(2707)$ & $73.2(655)$ & $<0.001$ \\
\hline Older siblings & $53.4(702)$ & $54.2(2065)$ & $61.7(409)$ & 0.001 \\
\hline Bedroom sharing & 65.3 (1774) & $66.9(4332)$ & $71.2(666)$ & 0.005 \\
\hline $\begin{array}{l}\text { Family history of } \\
\text { allergic disease }\end{array}$ & $37.9(883)$ & 31.5 (1714) & 26.4 (218) & $<0.001$ \\
\hline $\begin{array}{l}\text { Serious respiratory } \\
\text { infection }<5 \text { years }\end{array}$ & $12.2(319)$ & 10.7 (649) & $12.1(108)$ & 0.088 \\
\hline $\begin{array}{l}\text { School attendance } \\
<5 \text { years }\end{array}$ & 50.3 (1124) & 36.2 (2288) & $18.4(163)$ & $<0.001$ \\
\hline
\end{tabular}

*Statistical significance determined by $\chi^{2}$ or analysis of variance. 
Table 2 Associations between lung function measures and allergic disease outcomes with childhood home environment (inner city reference group)

\begin{tabular}{|c|c|c|c|c|c|}
\hline & Inner city, \% (n) & Village/town/suburb, \% (n) & Farm, \% (n) & $\begin{array}{l}\text { Village/town/suburb, } \\
\text { OR ( } 95 \% \mathrm{CI}) \text { or } \\
\text { mean difference (SD) }\end{array}$ & $\begin{array}{l}\text { Farm, } \\
\text { OR }(95 \% \mathrm{CI} \text { I) or } \\
\text { mean difference (SD) }\end{array}$ \\
\hline BHR & $18(306)$ & $16(625)$ & $12(78)$ & & \\
\hline +BHR - atopy & & & & $1.05(0.81$ to 1.36$)$ & $0.92(0.61$ to 1.39$)$ \\
\hline -BHR + atopy & & & & 0.82 (0.69 to 0.96$)$ & $0.46(0.34$ to 0.61$)$ \\
\hline +BHR + atopy & & & & $0.88(0.69$ to 1.11$)$ & $0.54(0.35$ to 0.83$)$ \\
\hline Mean $\mathrm{FEV}_{1} / \mathrm{FVC}(\mathrm{SD})^{*}$ & $80.2(6.8)$ & $80.0(6.7)$ & $80.6(6.8)$ & $-0.06(-0.41$ to 0.29$), p=0.746$ & 0.60 (0.04 to 1.16$), p=0.036$ \\
\hline Any atopic sensitisation & $38(771)$ & $31(1564)$ & $18(143)$ & $0.83(0.73$ to 0.94$)$ & $0.46(0.37$ to 0.58$)$ \\
\hline Nasal symptoms & $36(950)$ & 32 (1992) & $25(230)$ & & \\
\hline $\begin{array}{l}\text { +Nasal symptoms } \\
\text {-Atopy }\end{array}$ & & & & $1.04(0.87$ to 1.24$)$ & $0.96(0.73$ to 1.26$)$ \\
\hline $\begin{array}{l}\text {-Nasal symptoms } \\
+ \text { Atopy }\end{array}$ & & & & $0.76(0.64$ to 0.91$)$ & $0.51(0.37$ to 0.69$)$ \\
\hline $\begin{array}{l}\text { +Nasal symptoms } \\
\text { +Atopy }\end{array}$ & & & & $0.90(0.77$ to 1.05$)$ & $0.43(0.32$ to 0.57$)$ \\
\hline Current asthma & $6.1(168)$ & $5.5(361)$ & $4.4(41)$ & & \\
\hline $\begin{array}{l}\text { +Current asthma } \\
\text {-Atopy }\end{array}$ & & & & $1.08(0.72$ to 1.61$)$ & 1.09 (0.60 to 1.99$)$ \\
\hline $\begin{array}{l}\text {-Current asthma } \\
\text { +Atopy }\end{array}$ & & & & $0.82(0.72$ to 0.93$)$ & 0.47 (0.37 to 0.59$)$ \\
\hline $\begin{array}{l}\text { +Current asthma } \\
\text { +Atopy }\end{array}$ & & & & $0.92(0.70$ to 1.21$)$ & $0.47(0.28$ to 0.81$)$ \\
\hline $\begin{array}{l}\text { Statistically significant as } \\
\text { Adjustment for age, sex, } \\
\text { *Additional adjustment: } \\
\text { BHR, bronchial hyper-res }\end{array}$ & $\begin{array}{l}\text { tions are in bold. } \\
\text { centre, smoking an } \\
\mathrm{t}^{2} \text { and weight. } \\
\text { veness. }\end{array}$ & iily history of allergic disease. & & & \\
\hline
\end{tabular}

that the protective effect of the farming environment was limited to those with allergic nasal symptoms $(\mathrm{OR}=0.43,95 \%$ CI 0.32 to 0.57 ). Participants with early-life village, town or suburb, exposure did not have reduced risk of allergic nasal symptoms when compared with the inner city reference group. A similar pattern was observed for current allergic/non-allergic asthma in reference to place of upbringing, in which farm children experienced a significant reduction in the risk of allergic asthma by approximately $50 \%$. On the other hand, the risk of current allergic asthma for those participants from a village, town or suburb was not significantly reduced when compared with the inner city reference group. A very similar pattern was also observed in the analysis of allergic/non-allergic BHR in relation to childhood environment.

\section{Lung function}

An interaction $(p=0.03)$ was observed between gender and early-life home environment for $\mathrm{FEV}_{1}$ (table 3), but not $\mathrm{FEV}_{1}$ / FVC ratio. After adjustment for a priori confounders and weight, females from a childhood farming environment experienced a significantly higher $\mathrm{FEV}_{1}$ of approximately $110 \mathrm{~mL}$
(95\% CI 64 to 157). Slightly higher $\mathrm{FEV}_{1} / \mathrm{FVC}$ values were observed for those who lived on a farm before the age of 5 years $(0.60, p=0.036$, table 2$)$. However, this increase was found to be only modest after adjustment for maternal/paternal smoking and serious respiratory infections before the age of 5 years $(p=0.115)$. No significant associations were observed with $\mathrm{FEV}_{1} / \mathrm{FVC}$ categorised above and below 70\%. Also, a higher $\mathrm{FEV}_{1} / \mathrm{FVC}$ was not observed for village/town/suburb participants as compared with the inner city reference group.

\section{Meta-analysis of the effects}

No heterogeneity was seen between the associations of place of upbringing between countries for the outcome of allergic sensitisation (figure $1 ; \mathrm{I}^{2}=0 \%$ ), while some heterogeneity was observed for the outcome of $\mathrm{FEV}_{1}$ (figure $2 ; \mathrm{I}^{2}=44.8 \%$ ). The pooled risk estimate for any sensitisation in the farming subgroup indicates a $53 \%(95 \%$ CI 0.36 to 0.59$)$ reduction in the risk of sensitisation, while the village group had only $26 \%(95 \%$ CI 0.74 to 0.96 ) reduction when compared with individuals exposed to an inner city environment in early life. Higher FEV levels were observed in females with a farm upbringing when

Table 3 Lung function outcomes in relation to childhood living environment

\begin{tabular}{|c|c|c|c|c|}
\hline & \multicolumn{2}{|l|}{ Men } & \multicolumn{2}{|l|}{ Women } \\
\hline & Mean $\mathrm{FEV}_{1}, \mathrm{~L}(\mathrm{SD})$ & Adjusted difference in $\mathrm{FEV}_{1}, \mathrm{~mL}^{*}$ & Mean $\mathrm{FEV}_{1}, \mathrm{~L}(\mathrm{SD})$ & Adjusted difference in $\mathrm{FEV}_{1}, \mathrm{~mL}^{*}$ \\
\hline Inner city & $4.03(0.59)$ & (reference) & $2.97(0.40)$ & (reference) \\
\hline Village/town/suburb & $4.06(0.73)$ & $41(-5$ to 86$), p=0.080$ & $2.99(0.40)$ & $22(-7$ to 51$), p=0.142$ \\
\hline Farm & $4.08(0.59)$ & $52(-20$ to 124$), p=0.158$ & $3.08(0.40)$ & 110 (64 to 157$), p<0.001$ \\
\hline
\end{tabular}

*Adjusted for age, height ${ }^{2}$, weight, study centre, smoking and family history of allergic disease. 
Figure 1 Fixed-effect meta-analysis for odds of any sensitisation by early-life home environment for each participating country. For each centre, the square gives the $\mathrm{OR}$ and the horizontal lines indicate $95 \% \mathrm{Cl}$; the area of the square is proportional to the size of the study sample in each centre.
Figure 2 Random effects meta-analysis for mean difference in $\mathrm{FEV}_{1}$ by country for farm compared with inner city in females. For each country, the square gives the weighted mean difference (WMD) and the horizontal lines indicate $95 \% \mathrm{Cl}$; the area of the square is proportional to the size of the study sample in each country.
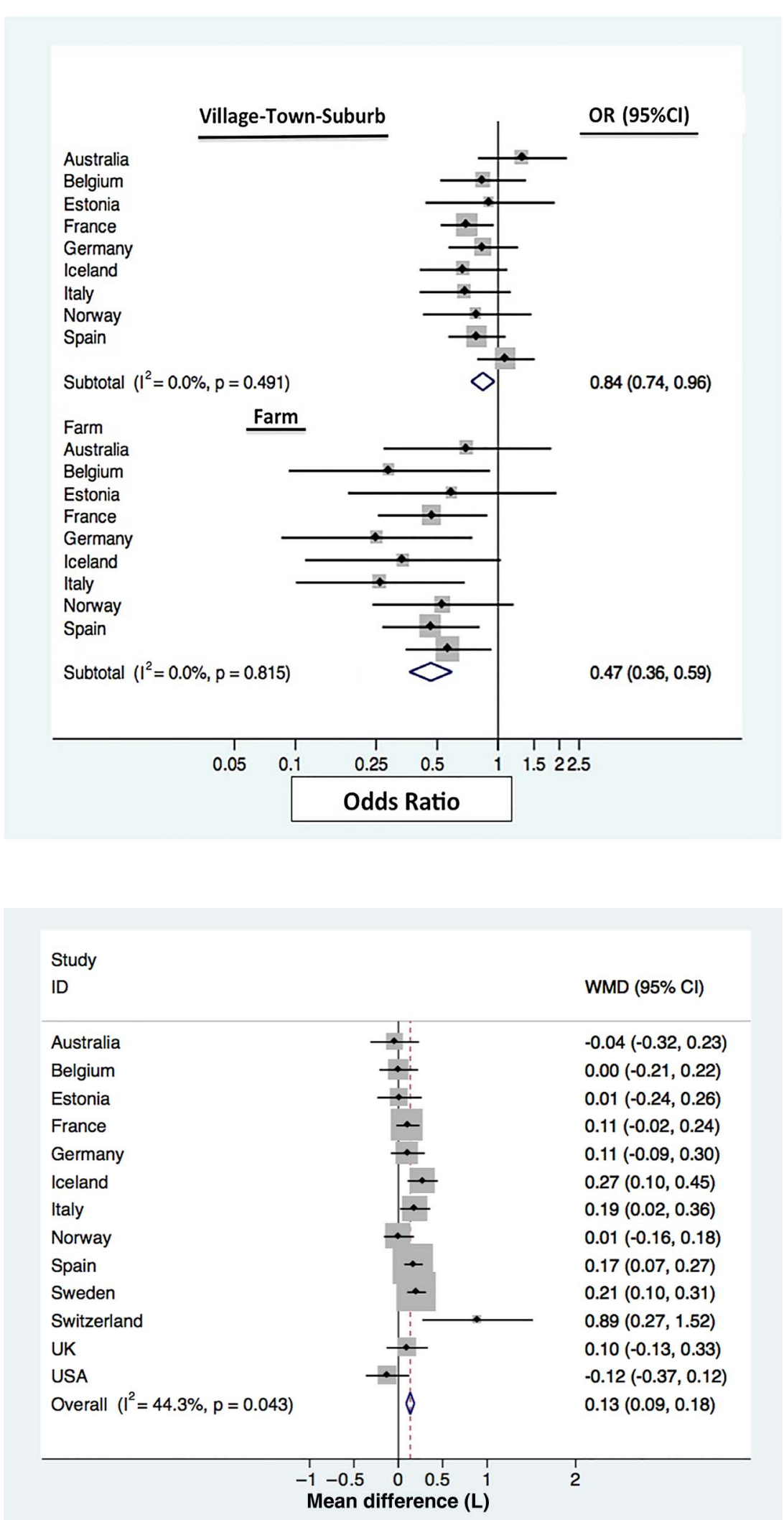

compared with those from an inner city (pooled mean $=0.13 \mathrm{~L}$, $95 \%$ CI 0.09 to 0.18 ).

\section{Subgroup analyses}

Descriptive statistics for each biodiversity score subgroup are displayed in table 4. Among those who lived in an inner city in the first 5 years of life, a reduction in risk of any sensitisation was observed with increasing proxy microbial load score (trend $\mathrm{p}=0.05$ ) (table 5). Similarly, for most outcomes, decreased odds of all allergic phenotypes were observed with increasing proxy microbial load score. However, as seen in table 5, early-life farming exposure was associated with a stronger reduction in 
Table 4 Characteristics and demographic data for the inner city study population, according to biodiversity score

\begin{tabular}{|c|c|c|c|c|c|c|c|}
\hline & $\begin{array}{l}\text { Score } 0, \\
\text { mean (SD) }\end{array}$ & $\begin{array}{l}\text { Score } 1, \\
\text { mean (SD) }\end{array}$ & $\begin{array}{l}\text { Score 2, } \\
\text { mean (SD) }\end{array}$ & $\begin{array}{l}\text { Score 3, } \\
\text { mean (SD) }\end{array}$ & $\begin{array}{l}\text { Score } 4, \\
\text { mean (SD) }\end{array}$ & $\begin{array}{l}\text { Score } 5, \\
\text { mean (SD) }\end{array}$ & p Value* \\
\hline \multirow[t]{2}{*}{ Mean age, years } & $43.6(7.3)$ & $43.7(7.3)$ & $42.3(7.3)$ & $42.2(7.3)$ & $41.9(7.0)$ & $39.9(7.4)$ & $<0.001$ \\
\hline & $\%(n)$ & $\%(n)$ & $\%(n)$ & $\%(n)$ & $\%(n)$ & $\%(n)$ & \\
\hline \multicolumn{8}{|l|}{ Gender } \\
\hline Male & $53.6(30)$ & $50.1(137)$ & $45.7(313)$ & $45.1(296)$ & $41.9(142)$ & $40.8(44)$ & \\
\hline Female & $46.4(26)$ & $49.8(136)$ & $54.3(372)$ & $54.9(361)$ & $58.1(197)$ & $59.3(64)$ & 0.243 \\
\hline Ever smoker & $48.2(27)$ & $61.3(166)$ & $55.8(381)$ & $58.0(380)$ & $64.3(218)$ & $62.0(67)$ & 0.058 \\
\hline Paternal smoking & $70.9(34)$ & $62.8(165)$ & $64.4(428)$ & $68.4(437)$ & $73.4(240)$ & $78.9(82)$ & 0.004 \\
\hline Maternal smoking & $27.3(15)$ & $23.3(62)$ & $25.1(169)$ & $24.8(161)$ & $32.9(110)$ & $34.3(37)$ & 0.020 \\
\hline Cat childhood & 0 & $3.9(11)$ & $12.9(95)$ & $36.0(247)$ & $72(249)$ & $100(108)$ & $<0.001$ \\
\hline Dog childhood & 0 & $5.6(16)$ & $9.8(72)$ & $31.6(217)$ & $71.4(247)$ & $100(108)$ & $<0.001$ \\
\hline Older siblings & 0 & $48.6(139)$ & $82.4(605)$ & $91.8(630)$ & $97.4(337)$ & $100(108)$ & $<0.001$ \\
\hline Bedroom sharing & 0 & $23.1(66)$ & $58.0(426)$ & $78.1(536)$ & $90.2(312)$ & $100(108)$ & 0.005 \\
\hline School attendance $<5$ years & 0 & $18.9(54)$ & $36.8(270)$ & $62.4(428)$ & $69.1(239)$ & $100(108)$ & $<0.001$ \\
\hline Family history of allergic disease & $31.9(15)$ & $33.8(78)$ & $32(191)$ & $35.4(204)$ & $31.8(93)$ & $33.3(31)$ & 0.849 \\
\hline Serious respiratory infection $<5$ years & $9.4(5)$ & $11.9(32)$ & $10.6(74)$ & $8.9(58)$ & $11.1(37)$ & $11.3(11)$ & 0.754 \\
\hline
\end{tabular}

*Statistical significance determined by $\chi^{2}$ or analysis of variance.

Table 5 Associations between lung function measures and allergic disease outcomes across varied biodiversity levels in an inner city childhood living environment (grouped by biodiversity score) and farm

\begin{tabular}{|c|c|c|c|c|c|}
\hline & $\begin{array}{l}\text { Biodiversity score 0/1, } \\
\text { inner city } \\
\text { reference }\end{array}$ & $\begin{array}{l}\text { Biodiversity score } 2, \\
\text { inner city }\end{array}$ & $\begin{array}{l}\text { Biodiversity score } 3, \\
\text { inner city }\end{array}$ & $\begin{array}{l}\text { Biodiversity score } 4 / 5 \text {, } \\
\text { inner city }\end{array}$ & Farm \\
\hline $\mathrm{FEV}_{1}{ }^{*}$ - $\mathrm{men}(\mathrm{mL})$ & - & $-16(-133$ to 101$)$ & $-56(-179$ to 67$)$ & $-91(-229$ to 46$)$ & $32(-90$ to 153$)$ \\
\hline $\mathrm{FEV}_{1}{ }^{*}$ 一women $(\mathrm{mL})$ & - & 11 ( -73 to 95$)$ & -9 (-96 to 77$)$ & $51(-41$ to 143$)$ & 116 (29 to 202$), p=0.009$ \\
\hline $\mathrm{FEV}_{1} / \mathrm{FVC}^{*}$ & - & $-0.22(-1.17$ to 0.72$)$ & $-0.44(-1.42$ to 0.54$)$ & $-0.43(-1.5$ to 0.64$)$ & $0.30(-0.67$ to 1.28$), p=0.545$ \\
\hline +BHR - atopy & - & 0.99 (0.51 to 1.91$)$ & 0.64 (0.31 to 1.32$)$ & 0.78 (0.36 to 1.68$)$ & 0.77 (0.39 to 1.51$)$ \\
\hline$-B H R+$ atopy & - & 0.66 (0.43 to 1.01$)$ & 0.72 (0.47 to 1.12$)$ & 0.54 (0.29 to 0.88$)$ & 0.31 (0.19 to 0.49 ) \\
\hline+ BHR + atopy & - & $0.83(0.43$ to 1.60$)$ & $0.80(0.41$ to 1.57$)$ & $0.96(0.47$ to 1.96$)$ & $0.46(0.23$ to 0.95$)$ \\
\hline Any atopic sensitisation & - & 0.81 (0.58 to 1.12$)$ & $0.76(0.54$ to 1.07$)$ & 0.70 (0.49 to 1.02$)$ & $0.36(0.25$ to 0.52$)$ \\
\hline $\begin{array}{l}\text { +Nasal symptoms } \\
\text { - atopy }\end{array}$ & - & 1.23 (0.78 to 1.96$)$ & 0.94 (0.58 to 1.51$)$ & 0.87 (0.52 to 1.46$)$ & 0.85 (0.55 to 1.32$)$ \\
\hline $\begin{array}{l}\text {-Nasal symptoms } \\
+ \text { atopy }\end{array}$ & - & 0.76 (0.49 to 1.18$)$ & $0.81(0.53$ to 1.26$)$ & $0.83(0.52$ to 1.33$)$ & $0.42(0.28$ to 0.66$)$ \\
\hline $\begin{array}{l}\text { +Nasal symptoms } \\
+ \text { atopy }\end{array}$ & - & 0.96 (0.65 to 1.42$)$ & 0.88 (0.59 to 1.31$)$ & 0.85 (0.55 to 1.31$)$ & $0.38(0.25$ to 0.56$)$ \\
\hline $\begin{array}{l}\text { +Current asthma } \\
\text { - atopy }\end{array}$ & - & $0.80(0.32$ to 2.00$)$ & 0.48 (0.17 to 1.34$)$ & 0.31 (0.08 to 1.11$)$ & 0.55 (0.21 to 1.41$)$ \\
\hline $\begin{array}{l}\text {-Current asthma } \\
+ \text { atopy }\end{array}$ & - & 0.77 (0.55 to 1.09$)$ & $0.70(0.49$ to 1.00$)$ & $0.61(0.41$ to 0.90$)$ & $0.34(0.23$ to 0.50$)$ \\
\hline $\begin{array}{l}\text { +Current asthma } \\
\text { + atopy }\end{array}$ & - & 1.16 (0.47 to 2.88$)$ & $1.26(0.50$ to 3.13$)$ & $1.57(0.60$ to 4.10$)$ & $0.56(0.21$ to 1.50$)$ \\
\hline
\end{tabular}

the risk of sensitisation and allergic disease phenotypes than any level of proxy microbial exposure in the inner city.

\section{DISCUSSION}

In this international study, interestingly, a higher $\mathrm{FEV}_{1}$ was observed only in females exposed to farming in the first 5 years of life independent of asthma and sensitisation, which to our knowledge has never been reported before. Furthermore, a protective effect of early-life farming exposure was observed on allergic sensitisation and, allergic phenotypes of nasal symptoms, asthma and BHR in adults, and while those raised on a rural setting had some reduction in the risk of sensitisation, this was not as strong as seen for those raised on a farm. The association between farm exposure and sensitisation was consistent across all countries participating in this study while the effect on $\mathrm{FEV}_{1}$ varied slightly across centres. Our findings on atopic sensitisation are consistent with an earlier ECRHS I analysis, conducted by Leynaert et al, ${ }^{22}$ comparing farm versus non-farm participants, which found a reduced risk of atopic sensitisation in adulthood (crude odds ratio (ORc) 0.68 , CI 95\% 0.55 to 0.86 ) with living on a farm in childhood, but no associations were observed for risk of asthma (ORc 0.82; CI 95\% 0.53 to 
1.27 ) or wheeze (ORc 1.09; CI 95\% 0.82 to 1.46). While earlylife exposures in the inner city related to increasing proxies of microbial diversity were also shown to be associated with a decreased risk of sensitisation, this reduction of risk was not as large as with farm exposure alone.

Our analysis of proxy markers of increasing microbial exposures indicated that within an urban environment increased exposure to microbial load may reduce the risk of atopic disease but the magnitude of this effect does not match that observed with farm exposure. It is possible that prolonged contact with unique farm exposures such as livestock with extensive microbial diversity are unmatched by any exposure in the inner city. These findings further support the role of both load and diversity in environmental exposures in the development of allergic diseases, as proposed by the 'microbial diversity hypothesis'. ${ }^{23-27}$ It is also relevant to consider the possibility that proxy measures such as pet, daycare and crowding exposure can represent alternate factors or mechanisms that influence disease risk in addition to microbial biodiversity, which could potentially influence the estimates related to our biodiversity score. Additionally, selective avoidance of pets due to asthma or allergy could also influence inner city biodiversity scores, but would likely only play a small role in our estimates. ${ }^{28}$ However, the overall findings from our analysis indicate that the diversity of early-life microbial exposures impacts disease outcomes later in adult life.

To date, the majority of work done on farm exposures has focused on the association between early-life farm contact and childhood allergic and respiratory disease outcomes, while very few studies have investigated the impact of early-farm contact on adult disease, and especially adult lung function. ${ }^{9}$ Our findings on the impact of farm exposure on lung function in women are novel. Differential response to a range of environmental exposures, such as microbial diversity, indoor environment and air pollution, might possibly contribute to this gender difference. Further, the actual exposures related to urban and rural environment might differ between men and women. It is possible that men work in different roles or for longer periods on a farm than females, to a point where their exposure levels become harmful instead of protective. ${ }^{29}$ The social differences around standards of cleanliness for males and females could also impact the function of the hygiene hypothesis in relation to sex. ${ }^{30}$ A sex-dependent functioning of the 'farm-effect' has been observed in children or adolescents in relation to the cumulative incidence of asthma and in adults with early-life farm exposure in relation to asthma, hay fever and atopy. ${ }^{29} 3132$ In addition, gender differences have already been explored in relation to other environmental exposures and lung health and allergic disease outcomes. In a recent study by Mészáros et al, ${ }^{33}$ exposure to home environmental tobacco smoke was found to increase the odds of current asthma only in males. Although the findings have been inconsistent, gender differences in response to air pollution have also been reported. ${ }^{34} 35$

Gene-environment interactions have also been reported to play a crucial role in the association between farming and allergic/respiratory disease outcomes. ${ }^{36}{ }^{37}$ It is suggested that those genetically susceptible may be at a higher risk of allergies and respiratory outcomes when exposed to farming, and such groups may select themselves out of farming populations. Interestingly, we observed those with farming exposure to have a lower prevalence of family history of allergies supporting this hypothesis.

Our recent review consolidated published literature showing significant interactions between CD14 gene polymorphisms and environmental microbial exposures with evidence of a protective effect on atopic disease in childhood. ${ }^{37}$ Additional evidence has also shown that the expression of toll-like receptor 2 (TLR2) genes may differ between farm and non-farm children, and it is believed that some TLRs may act through various pathways to modify the risk of allergic or respiratory diseases. ${ }^{38} 39$ It has also been hypothesised that polymorphisms in oxidative stress genes may play a role in gene-environmental pollutant interactions that impact allergic and respiratory disease. However, investigations into the modification of respiratory disease risk through an altered oxidative stress response related to genetic variants of $\mathrm{NAD}(\mathrm{P}) \mathrm{H}$ :quinone acceptor oxidoreductase 1 (NQO1) and glutathione $S$-transferase (GST) genes, have shown mixed results. ${ }^{40}$ The above discussion highlights that multiple genes may modify the role in the observed 'farm effect', and that future research into this field needs to take into account a number of potential environmental and genetic modifiers.

The strength of our study is that it is a well-powered multinational study on adult asthma and atopy, which collected various exposure data and objective clinical measures of atopic sensitisation and lung function by a standardised protocol. The potential limitations of this study are survey data on early-life exposures collected retrospectively and no objective measures of microbial diversity were available for comparison. Residual confounding, stemming from a wide variety of exposures associated with different living environments as mentioned above, may also be present in this analysis. These uncontrolled confounders may all contribute to the observed 'farm effect' in a unique way that should be teased out in future investigations. Finally, selfselection out of farm life for those with a family history of allergic disease can present bias. Although we have adjusted for a family history of allergic disease in our analyses, an amount of residual confounding may remain based on the severity of allergic disease symptoms. Without further exploration into early-life clinical outcomes such as lung function or age at disease onset, we are unable to completely determine whether effects on adult lung function or disease are arising as a result of the direct effect of childhood farm exposure on adult health or mediated through distinct effects on childhood disease. It is also possible that adult exposures, such as occupational or home environment, may modify the effect of early-life exposures on adult disease; however, no significant interactions were observed between early-life home environment and adult cleaning or agriculture occupations in these analyses.

\section{CONCLUSIONS}

Consistently across 14 countries, this analysis shows that earlylife exposure to farm environments is protective against subsequent adult allergic diseases. The consistency of the findings across multicountry settings suggests that farming effects may be due to biological mechanisms rather than socio-cultural effects that would differ between countries. A novel finding was that women who grew up on a farm had higher lung function, and only mild heterogeneity was observed across 14 countries. Further work is necessary to explain gender differences. Our analysis further showed protective effects of markers of microbial diversity (pets, siblings, day care, etc) in persons with an inner city background, however, not as strong as protective effects related to farm upbringing. Future studies should aim to discern critical farm exposures that drive the association with sensitisation by exploring the microbial components of farm environments through molecular studies.

\section{Author affiliations}

${ }^{1}$ Allergy \& Lung Health Unit, Centre for Epidemiology \& Biostatistics, The University of Melbourne, Melbourne, Victoria, Australia 
${ }^{2}$ Unité Epidémiologie et Biostatistique, Université Bordeaux Segalen, Bordeaux, France

${ }^{3}$ Murdoch Children's Research Institute, Melbourne, Australia

${ }^{4}$ Department of Respiratory Medicine and Sleep, Landspitali University Hospital, Reykjavik, Iceland

${ }^{5}$ Faculty of Medicine, University of Iceland, Reykjavik, Iceland

${ }^{6}$ Instititute of Epidemiology I, German Research Centre for Environmental Health, Helmholtz Zentrum München, Neuherberg, Germany

${ }^{7}$ Institute and Outpatient Clinic for Occupational, Social and Environmental Medicine, University Hospital Munich, Ludwig-Maximilians University Munich, Munich, Germany

${ }^{8}$ Centre for Research in Environmental Epidemiology (CREAL), Barcelona, Spain

${ }^{9} \mathrm{CIBER}$ Epidemiología y Salud Pública (CIBERESP), Barcelona, Spain

${ }^{10}$ Departament de Ciències Experimentals i de la Salut (UPF), Universitat Pompeu Fabra, Barcelona, Spain

${ }^{11}$ Department of Occupational Medicine, Haukeland University Hospital, Bergen, Norway

${ }^{12}$ Centre for International Health, University of Bergen, Norway

${ }^{13}$ Department of Medical Sciences; Occupational and Environmental Medicine,

Uppsala University, Uppsala, Sweden

${ }^{14}$ Institute of Lung Biology and Health (iLBD), Comprehensive Pneumology Center

(CPC), Helmholtz Zentrum München, Munich-Neuherberg, Germany

${ }^{15}$ Epidemiology and Public Health, Swiss Tropical and Public Health Institute, Basel, Switzerland

${ }^{16}$ University of Basel, Basel, Switzerland

${ }^{17}$ Epidemiology and Medical Statistics, University of Verona, Verona, Italy

${ }^{18}$ National Heart and Lung Institute, Imperial College, London, UK

${ }^{19}$ Section for Environment Occupation and Health, Department of Public Health,

Aarhus University, Aarhus, Denmark

${ }^{20}$ Centre de Recherche Albert Bonniot, Grenoble, France

Acknowledgements The ECRHS study is a joint project with multiple PIs and funded by many sources. This report uses information from ECRHS I and ECRHS II PIs and research staff have changed over the years but for these phases include: Project Leader: Peter Burney; Statistician: Sue Chinn; Principal Investigator: Deborah Jarvis; Project Coordinator: Jill Knox; Principal Investigator: Christina Luczynska; Assistant Statistician: J. Potts; Data Manager: S. Arinze. Steering Committee: Josep M. Anto, Institut Municipal d'Investigac oMedica (IMIM-IMAS), Uni-versitat Pompeu Fabra (UPF): Peter Burney, Imperial College, London (Project Leader); Isa Cerveri, University of Pavia; Susan Chinn, King's College, London; Roberto de Marco, University of Verona; Thorarinn Gislason, Iceland University Hospital; Joachim Heinrich, GSF-Institute of Epidemiology; Christer Janson, Uppsala University; Deborah Jarvis, Imperial College London; Nino Kunzli, formerly University of Basel, now University of Southern California Los Angeles; Benedicte Leynaert, Institut National de la Santeet de la Recherche Medicale (INSERM); Françoise Neukirch, Institut National de la Sante et de la Recherche Medicale (INSERM); J. Schouten, University of Groningen; Jordi Sunyer, Institut Municipal d'Investigacio Medica (IMIM-IMAS), Universitat Pompeu Fabra (UPF); Cecilie Svanes, University of Bergen; Vermeire, University of Antwerp; MatthiasWjst, GSF_-Institute of Epidemiology and Technical University Munchen. Principal Investigators and Senior Scientific Team: Belgium: South Antwerp \& Antwerp City (P. Vermeire, J. Weyler, M. Van Sprundel, V. Nelen). Estonia: Tartu (R. Jogi, A. Soon). France: Paris (F. Neukirch, B. Leynaert, R. Liard, M. Zureik), Grenoble (I. Pin, J. Ferran-Quentin). Germany: Erfurt (J. Heinrich, M. Wjst, C. Frye, I. Meyer). Iceland: Reykjavik (T. Gislason, E. Bjornsson, D. Gislason, T. Blondal, K.B. Jorundsdottir). Italy: Turin (M. Bugiani, P. Piccioni, E. Caria, A. Carosso, E. Migliore, G. Castiglioni), Verona (R. de Marco, G. Verlato, E. Zanolin, S. Accordini, A. Poli, V. Lo Cascio, M. Ferrari), Pavia (A. Marinoni, S. Villani, M. Ponzio, F. Frigerio, M. Comelli, M. Grassi, I. Cerveri, A. Corsico). The Netherlands: Groningen \& Geleen (J. Schouten, M. Kerkhof). Norway: Bergen (A. Gulsvik, E. Omenaas, C. Svanes, B. Laerum). Spain: Barcelona (J.M. Anto, J. Sunyer, M. Kogevinas, J.P. Zock, X. Basagana, A. Jaen, F. Burgos), Huelva (J. Maldonado, A. Pereira, J.L. Sanchez), Albacete (J. Martinez-Moratalla Rovira, E. Almar), Galdakao (N. Muniozguren, I. Urritia), Oviedo (F. Payo). Sweden: Uppsala (C. Janson, G. Boman, D. Norback, M. Gunnbjornsdottir), Goteborg (K. Toren, L. Lillienberg, A.C. Olin, B. Balder, A. Pfeifer-Nilsson, R. Sundberg), Umea (E. Norrman, M. Soderberg, K. Franklin, B. Lundback, B. Forsberg, L. Nystrom). Switzerland: Basel (N. Kunzli, B. Dibbert, M. Hazenkamp, M. Brutsche, U. Ackermann-Liebrich). United Kingdom: Norwich (D. Jarvis, B. Harrison), Ipswich (D. Jarvis, R. Hall, D. Seaton).

Competing interests None declared.

Ethics approval Multinational study with various approving bodies.

Provenance and peer review Not commissioned; externally peer reviewed.

\section{REFERENCES}

Strachan DP. Hay fever, hygiene, and household size. BMJ 1989;299:1259-60.
2 von Mutius E, Vercelli D. Farm living: effects on childhood asthma and allergy. Nat Rev Immunol 2010;10:861-8.

3 Genuneit J. Exposure to farming environments in childhood and asthma and wheeze in rural populations: a systematic review with meta-analysis. Pediatr Allergy Immunol 2012;23:509-18.

4 Braun-Fahrländer C, Riedler J, Herz U, et al. Environmental exposure to endotoxin and its relation to asthma in school-age children. N Engl J Med 2002;347:869-77.

5 Schram-Bijkerk D, Doekes G, Douwes J, et al. Bacterial and fungal agents in house dust and wheeze in children: the PARSIFAL study. Clin Exp Allergy 2005;35:1272-8

6 Thorne PS, Kulhánková K, Yin M, et al. Endotoxin exposure is a risk factor for asthma: The National survey of endotoxin in United States housing. Am J Respir Crit Care Med 2005:172:1371-7.

7 van Strien RT, Engel R, Holst O, et al. Microbial exposure of rural school children, as assessed by levels of $\mathrm{N}$-acetyl-muramic acid in mattress dust, and its association with respiratory health. J Allergy Clin Immunol 2004;113:860-7.

8 von Mutius E, Braun-Fahrländer C, Schierl R, et al. Exposure to endotoxin or other bacterial components might protect against the development of atopy. Clin Exp Allergy 2000;30:1230-4

9 Campbell BE, Lodge CJ, Lowe AJ, et al. Exposure to "farming" and objective markers of atopy: a systematic review and meta-analysis. Clin Exp Allergy 2015:45:744-57

10 Portengen L, Sigsgaard T, Omland $\varnothing$, et al. Low prevalence of atopy in young danish farmers and farming students born and raised on a farm. Clin Exp Allergy 2002;32:247-53

11 Schulze A, van Strien RT, Praml G, et al. Characterization of asthma among adults with and without childhood farm contact. Eur Respir J 2007;29:1169-73.

12 Fuchs 0 , Genuneit J, Latzin $\mathrm{P}$, et al. Farming environments and childhood atopy, wheeze, lung function, and exhaled nitric oxide. J Allergy Clin Immunol 2012;130:382-8.e6

13 Ernst $\mathrm{P}$, Cormier $Y$. Relative scarcity of asthma and atopy among rural adolescents raised on a farm. Am J Respir Crit Care Med 2000;161:1563-6.

14 Merchant JA, Naleway AL, Svendsen ER, et al. Asthma and farm exposures in a cohort of rural lowa children. Environ Health Perspect 2005;113:350-6.

15 Nicolaou N, Siddique N, Custovic A. Allergic disease in urban and rural populations: increasing prevalence with increasing urbanization. Allergy 2005:60:1357-60.

16 Vargas C, Bustos P, Diaz PV, et al. Childhood environment and atopic conditions, with emphasis on asthma in a Chilean agricultural area. J Asthma 2008:45:73-8.

17 Azad MB, Konya T, Maughan $\mathrm{H}$, et al. Infant gut microbiota and the hygiene hypothesis of allergic disease: impact of household pets and siblings on microbiota composition and diversity. Allergy Asthma Clin Immunol 2013;9:15.

18 Calvani M Jr, Alessandri C, Bonci E. Fever episodes in early life and the development of atopy in children with asthma. Eur Respir J 2002;20:391-6.

19 Burney PG, Luczynska C, Chinn S, et al. The European Community Respiratory Health Survey. Eur Respir J 1994;7:954-60.

20 European Community Respiratory Health Survey II Steering Committee. The European Community Respiratory Health Survey II. Eur Respir J 2002;20:1071-9.

21 Dharmage S, Bailey M, Raven J, et al. Current indoor allergen levels of fungi and cats, but not house dust mites, influence allergy and asthma in adults with high dust mite exposure. Am J Respir Crit Care Med 2001;164:65-71.

22 Leynaert B, Neukirch C, Jarvis D, et al. Does living on a farm during childhood protect against asthma, allergic rhinitis, and atopy in adulthood? Am J Respir Crit Care Med 2001;164Pt 1):1829-34.

23 Lluis A, Depner M, Gaugler B, et al. Increased regulatory T-cell numbers are associated with farm milk exposure and lower atopic sensitization and asthma in childhood. J Allergy Clin Immunol 2014;133:551-9.

24 Naleway AL. Asthma and atopy in rural children: is farming protective? Clin Med Res 2004:2:5-12.

25 Downs SH, Marks GB, Mitakakis TZ, et al. Having lived on a farm and protection against allergic diseases in Australia. Clin Exp Allergy 2001;31:570-5.

26 Illi S, Depner M, Genuneit J, et al. Protection from childhood asthma and allergy in Alpine farm environments-the GABRIEL Advanced Studies. J Allergy Clin Immunol 2012:129:1470-7.e6.

27 Riedler J, Braun-Fahrländer C, Eder W, et al. Exposure to farming in early life and development of asthma and allergy: a cross-sectional survey. Lancet 2001;358:1129-33.

28 Svanes C, Zock JP, Antó J, et al. Do asthma and allergy influence subsequent pet keeping? An analysis of childhood and adulthood. J Allergy Clin Immunol 2006:118:691-8

29 Genuneit J. Sex-Specific Development of Asthma Differs between Farm and Nonfarm Children: A Cohort Study. Am J Respir Crit Care Med 2014;190:588-90.

30 Clough S. Gender and the hygiene hypothesis. Soc Sci Med 2011;72:486-93.

31 Rennie DC, Karunanayake $C P$, Chen $Y$, et al. Early farm residency and prevalence of asthma and hay fever in adults. J Asthma 2016:53:2-10.

32 Rennie DC, Lawson JA, Karunanayake CP, et al. Farm Exposure and Atopy in Men and Women: The Saskatchewan Rural Health Study. J Agromedicine 2015;20:302-9 
33 Mészáros D, Burgess J, Walters EH, et al. Domestic airborne pollutants and asthma and respiratory symptoms in middle age. Respirology 2014;19:411-18.

34 Mann JK, Balmes JR, Bruckner TA, et al. Short-term effects of air pollution on wheeze in asthmatic children in Fresno, California. Environ Health Perspect 2010;118:1497-502.

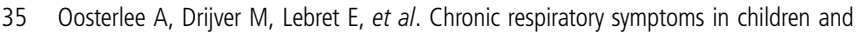
adults living along streets with high traffic density. Occup Environ Med 1996:53:241-7.

36 de Jong K, Boezen HM, Hacken NH, et al., LifeLines cohort study. GST-omega genes interact with environmental tobacco smoke on adult level of lung function. Respir Res 2013;14:83.
37 Lau MYZ, Dharmage SC, Burgess JA, et al. CD14 polymorphisms, microbial exposure and allergic diseases: a systematic review of gene-environment interactions. Allergy 2014;69:1440-53.

38 Lauener RP, Birchler T, Adamski J, et al. Expression of CD14 and Toll-like receptor 2 in farmers' and non-farmers' children. Lancet 2002;360:465-6.

39 Klaassen EM, Thönissen BE, van Eys G, et al. A systematic review of CD14 and toll-like receptors in relation to asthma in Caucasian children. Allergy Asthma Clin Immunol 2013;9:10.

40 Minelli C, Wei I, Sagoo G, et al. Interactive effects of antioxidant genes and air pollution on respiratory function and airway disease: a HuGE review. Am J Epidemiol 2011;173:603-20. 